\title{
Introduction to the Special Issue on Law and Literature
}

\author{
Julia J. A. Shaw
}

Published online: 18 December 2013

(C) Springer Science+Business Media Dordrecht 2013

The aesthetic dimension remains an essential component, the raw material, of human experience. Since the primary mode of human interaction is by means of spoken and written language, it is through the application of narrative and 'narrative imagination' that our lives can have meaning. If we accept Oscar Wilde's claim in The Decay of Lying that 'life imitates art', then by appealing to the literary imagination it is also possible to appreciate and empathise with the experiences of others; people of whom we have no firsthand knowledge and whose lives are far removed from our own (Wilde 2010). In an era of disillusionment legal scholarship often takes an aesthetic turn, manifesting a yearning for the beautiful which belongs to the imagery of liberation. It represents free play of the imagination and assists in our understanding of the world through our senses, as alternately beautiful and grotesque, alluring and repellent. The communicative power of this sensory information allows for richer intellectual and emotional engagement with objects and concepts as they really are, according to their sensible essence.

Without the influence of aesthetics in the formation of legal concepts, law would lose most of its persuasive force. Whereas by engaging with law through the liberal arts, we become more conscious of a multiplicity of dissident perspectives and sensuous content from which to inform our individual life choices and importantly influence our capacity for moral judgment. This proposition can be understood in semiotic terms on the basis that we respond to images and experiences which resonate with an individual or shared history of particular cultural traditions and practices. Our sensate relation to these symbols and metaphors constitutes a productive force which, in relation to the legal community, can be understood as underpinning the formation of legal principle and judgment. The persuasive influence of those aesthetic forms which rely on narrative and imagery-such as 
poetry, performance art, the play and of course the novel-is at least partially due to their cultural embeddedness. After all, the legal culture is itself, simultaneously, a co-producer and by-product of such cultural forms. Law is not only a system of social order, but also a method of creating meaning and a critical constituent of modern culture.

Scholars of law and literature have championed a variety of literary forms, as a rich source of material which exposes the harshness of conventional legal doctrine and allows us to imagine a situation in advance and work out its consequences. The law and literature relationship is, therefore, a particularly valuable locus for scrutinising the wider impact of narrative on improving the cold abstractions of law in relation to its empathic response to suffering. The application of narrative empathy in legal reasoning encourages a sympathetic consideration of those circumstances which impact on socially marginal groups, against the stereotyping and stultifying effects of arbitrary rule formalism. In Poethics and Other Strategies of Law and Literature, it is proposed that only literature can reanimate the ethical dimension of law, as aesthetic integrity leads to moral integrity or 'no bad judicial opinion can be well-written' (Weisberg 1992). It would seem that law needs a jurisprudence of good poetry rather than bad principles.

This special issue brings together a collection of papers presented at the recent annual Socio-Legal Studies Association Conference, which address a range of literary forms, fiction, theories and methodologies in relation to their intersection with law and legal dogma. The first essay, by academic lawyer and playwright Catrin Fflur Huws, juxtaposes the personal life and work of brilliant mathematician and Enigma code-breaker Alan Turing in relation to a range of questions relating to the mechanistic nature of reality, free will and the law. As a homosexual man living in a hypocritical, sexually repressive society, his conviction for gross indecency and being branded a security risk in 1952 is widely-considered by today's standards to be shameful; also ironic considering his machine helped to end Hitler's regime of prosecuting and gassing homosexual men. Following a campaign by prominent scientists including Stephen Hawking and almost 50 years after his death by suicide, Turing is set to be posthumously pardoned by a parliamentary bill that would quash the conviction; subsequent to the House of Lords approval of the latest stage of the bill without debate. This essay investigates a series of research issues relating to the law, gender and Turing machines raised by the play To Kill a Machine written by the author and first performed in 2012. More specifically, it considers whether and to what extent the law may be considered as a Turing machine. The point of the essay is not so much to settle the question one way or the other, but rather to suggest the possible avenues for future research emerging from the play. A set of thoughtprovoking questions are posed via a discussion that addresses challengingly diverse materials; these relate to two seminal texts by Alan Turing on machine computation, Turing's own biography and his encounters with the courts, legal theory and history, also analytical philosophy.

Shakespeare refers to law more than any other profession; integrating the work of lawyers and the law into his plays as a significant part of the cultural fabric of society. In many instances, the content of his plays reflects contemporary legal reality in their portrayal of the legal world as complex, deep-rooted and implicit rather than 
overstated or embellished for dramatic effect. This is illustrated by a variety of books and articles which have been written on law in Shakespeare and on his use of legal language and metaphor. Camilla Barker offers a range of textual examples from four plays (Comedy of Errors, The Merchant of Venice, Cymbeline and The Tempest) to explore the eternal question: to what extent liberty is protected by law? Rather than scrutinising the typical political plays, such as Henry VI, Richard III, Antony and Cleopatra and Coriolanus, that question more explicitly the nature of law and its power, such questions are explored through the lens of plays that are not their obvious territory. This selection aptly demonstrates the continuing relevance of Shakespeare to twenty-first century socio-legal thought. The analysis of Errors addresses marital partnerships, class differences and rights to legal participation, whilst Merchant considers socio-cultural identity, native-alien conflict and other legal obligations such as contracts and wills; offering deep insights into family and commercial law. Cymbeline addresses the role of empire as a force of liberation and restraint as well as of cultural knowledge, whilst The Tempest documents Prospero's quest for justice; touching on issues which are relevant to constitutional and administrative law. Each of the four plays is concerned with the exercise of autonomy and personal liberties, yet all lead to the rather perturbing conclusion that only the influential, wealthy and white male classes are fully successful: plus ça change, plus c'est la même chose. In spite of their historical situations, the plays are highly relevant to Human Rights Law and this is perhaps the principal modern legal arena that defines and shapes individual liberty. As this essay elucidates, it seems that almost the entire range of legal disciplines, whether dealing with private or public law, is revealed through the Shakespearean prism as an inherently flawed structure in which liberty is condemned to be reduced or restricted.

The third addition to this edited collection discusses the use of ideographs and other literary devices, particularly with reference to their application to emotional judgment. There is a steadily increasing and diverse body of research which explicates the influence of specific emotions in regulation, particularly by criminologists, sociolinguists and socio-legal theorists. Without emotion, the communicative possibilities of language and consequently identity are constrained and it is argued that the act of judgment or formulating an opinion is bound together with both the passions and the art of rhetoric (Shaw 2012). Emotions are presented as highly functional and adaptive phenomena, having essential evolutionary significance in individual as well as in social and cultural terms, along with the ability to tell the story of humanity. To produce a collective social reality requires accessing the world of social relations and, significantly, acknowledging the intrinsic emotional nature of humans and the impulsive attachment of particular sensorial meaning to their own activities and intentions. Emotions emerge from, and at least partially constitute, all individual choices and actions, and cannot be easily disregarded or set aside. They play a part in facilitating the possibility of the fullest and most meaningful interaction with others in the world, which is important because, as Beauvoir articulates, 'man can find justification of his own existence only in the existence of other men' (de Beauvoir 2000). By means of such emotions as sympathy, admiration and fear we can identify with the predicament of others; expanding our innate sense of human needs and interests. It is further submitted by 
the authors that emotionality is a critical component of reasonable, rational decision-making.

Even though emotionality is demonstrated to underpin legal discourse and much judicial rhetoric, the prevalence of the myth of judicial dispassion continues to be a cultural script of unusual longevity and potency, as judges continue to insist that their reasoning should never be clouded by emotion in the courtroom. This tendency to deny the influence and utility of emotional sense persists in spite of interdisciplinary research that illustrates the practical potential of applying 'appropriate' emotions in judgment. Evidence suggests they may even assist in normative thinking about the law, in terms of either its amelioration or its role in determining the affective lives of its subjects. The essay argues that the involvement of emotions and affective states does not nullify or vitiate fair punishment and retribution provisions; rather the identification of affective drives could help to distinguish between the right and wrong type of motivation and may even facilitate the formation of moral judgments. The authors conclude that the legal community must recognise its affinities with the passions, acknowledge the constructive influence of emotions on judgment and in shaping legal culture also law's rich rhetoric, and then consciously admit the best possibilities into the legal lexicon.

In the fourth essay, Robert Herian considers the relationship between desire, language, proscription (law) and the psychic space of the subject in Henry Miller's short story, Via Dieppe-Newhaven. The event at the heart of the story took place in 1935; it depicts a tedious and spiteful England in which the impecunious Miller is deported back to France the day after being interrogated by immigration officers and kept in jail overnight. Although this was not the outcome he envisaged, he was happy to return to France, albeit with a renewed understanding that all life is voyage or 'voyage within voyage'. As George Orwell surmised in his Collected Essays, Journalism and Letters 1945-1950, 'a couple of bureaucrats had got an artist at their mercy and the mixture of spite, cunning and stupidity with which they handled him made one wonder what is the use of all this talk about democracy and freedom of the press' (Orwell 1968). Miller's original reason for the trip across the La Manche was his desire to speak English having grown tired of hearing French spoken every day, and to escape his wife. More specifically he wanted to 'hear English spoken $24 \mathrm{~h}$ of the day, and nothing but English' in his intended destination London (Miller 1961). He did not get what he wanted and this essay discusses the idea of desire as sustained by fantasy and based on lack; enjoyment or pleasure, as corollaries of desire, are seemingly always deferred. The primary issue is whether Miller, or any individual, can, should or be encouraged to pursue what they want. This matter is approached from a Lacanian perspective in relation to both identification of, and with, the object of desire and an ongoing search for that object. In an exploration of the intersection of law and the subject with language, the author proposes that the use of language to articulate a desire for language comprises the endless refraction of holding a mirror up to a mirror; however this is only the case if language itself is understood as a lifeless tool of communication that simply relays meaning without affecting it. The author makes subtle use of psychoanalytic theory to connect language, desire, altered and 'the quest' while at the same time keeping an eye on obstacles to the journey in the form of various proscriptions. 
The final essay, Monsters, Heroes, Martyrs and their Storytellers, discusses the complicated and interdependent relationship between narrative, power and ideology, and unpacks the role of narrative as a socially symbolic act. The claim that legal traditions 'can only be understood through familiar narratives' and similarly 'international law would be meaningless without narrative', resonates with the view of Fredric Jameson in The Political Unconscious. In relation to the political interpretation of literary texts, he also stated that narratives comprise 'the absolute horizon of all reading and all interpretation' (Jameson 1981). The corollary of this view is that narrative serves as a potentially legitimating device for dominant ideological forms such as law. The resulting discursive closure not only places restrictions on the range of interpretations and meanings that can be attached to specific events or activities, it also distorts and represents the interests of particular groups. Narrative closure and narrative privilege as 'the natural order of things' evolve not only because of particular power structures, but rather they are maintained and reproduced because of those same constructs. Lynsey Mitchell elaborates on the various ways in which, by acquiescing to the traditional binary oppositions of good versus evil and a heroic narrative, it becomes impossible to fully appreciate or accurately debate complex cultural and political issues. Assumption of the heroic narrative, therefore, is argued to be a politicallymotivated way of articulating a particular system of meaning which privileges certain interests over others. Examples from legal to non-legal literature which discuss the 'War on Terror', particularly in relation to Afghan women, are used to illustrate the damaging influence of reductive and familiar cultural narratives that are purported to serve a propagandistic pro-militaristic function.

This late modern era of unprecedented economic, political and social upheaval has produced novel legal conundrums, the determination of which necessitates more than the application of bare technical or specialist knowledge. If the main aim of university research and scholarship is the pursuit of knowledge then, in this age of disenchantment, it is opportune to extend its reach beyond the boundaries of monopolistic claims of ownership over ideas, genres, disciplines or privileged methodological frameworks (Feenan 2009). It is suggested that the complex interpretative and cultural phenomenon of law requires that the legal scholar and modern lawyer be intellectually prepared to address often multifaceted and sensitive issues from alternative perspectives, by engaging with the multiple languages of law in the spirit of transdisciplinary or creative inquiry. Literature, for example, is not merely a mirror to law. Peter Goodrich and Jacques Derrida have both insisted that law be treated as literature; in that the force of meaning and language work through literature and are, therefore, already embedded within law as a textual and communicative structure. Scholars of legal discourse similarly hold that law is discourse and that discourse is an operative form of law (Manderson 2000). Each essay in this collection engages with, individually, a variety of themes relating to the relevance and appropriateness of the liberal arts to law. By intersecting with those aesthetic forms which seek to address the practical and conceptual needs of wider society, the purpose is not to transcend the traditional foundation of legal knowledge, rather to transform it. To this end the authors employ a diverse range of theoretical and empirical methodologies which critically reflect on how, by adopting 
a literary approach, it is possible to better understand and engage with the law in relation to the humanities and, significantly, humanity.

Acknowledgments I would like to thank all the contributors and reviewers for their respective endeavours. With regard to the provision of useful suggestions, constructive criticism and general support, I would like to express my gratitude to Hillary Shaw, Yves Abrioux and Shulamit Almog.

\section{References}

de Beauvoir, S. 2000. The ethics of ambiguity, 17. New York: Citadel Press.

Feenan, D. 2009. Socio-legal studies and the humanities. International Journal of Law in Context 5(3): 240.

Jameson, F. 1981. The political unconscious: Narrative as a socially symbolic act, 17. Ithaca: Cornell University Press.

Orwell, G. 1968. The collected essays, journalism and letters of George Orwell volume 4: in front of your nose 1945-1950, 107. London: Secker and Warburg.

Manderson, D. 2000. Transdisciplinarity: A new metaphysics? In Transdisciplinarity: Recreating Integrated Knowledge, eds. Margaret, Somerville., David, Rapport., 98. Oxford: EOLSS Publishers.

Miller, H. 1961. The cosmological eye, 200. New York: New Directions.

Shaw, J.J.A. 2012. The continuing relevance of Ars Poetica to legal scholarship and the modern lawyer. International Journal for the Semiotics of Law 25(1): 72.

Weisberg, R. 1992. Poethics and other strategies of law and literature, 81-83. Columbia: Columbia University Press.

Wilde, O. 2010. The decay of lying and other essays. London: Penguin Classics. 